\title{
Evaluation of Modulus of Elasticity of Candle Wax Modified HMA Concretes Using Hondros Model from Indirect Tensile Test
}

\author{
Enwuso Aleruchi Igwe*, Pere Kormane Fun-Akpo \\ Department of Civil Engineering \\ Rivers State University of Science and Technology, \\ Port Harcourt, Rivers State, Nigeria
}

*Corresponding Author: Enwuso Aleruchi Igwe, Department of Civil Engineering, Rivers State University of Science and Technology, Port Harcourt, Rivers State, Nigeria

\begin{abstract}
Design of flexible pavement systems usually requires laboratory testing techniques in order that the pavement materials are properly characterized. Characterization involves performance evaluation of pavement materials used for design and construction of pavement using specified techniques. The philosophy underneath characterization of the materials being to evaluate certain properties of the materials that make up the pavement layers such that it is believed that the pavement performance and life within the design period will not be compromised. On this basis the research studied the performance evaluation of a candle waxed modified HMA concrete with respect to elastic modulus as an input parameter in mechanistic design of pavements. Concretes were prepared for both unblended and blended mixes using candle wax in accordance with Marshall Design procedure and crushed using the indirect tensile splitting test method. Three categories of traffic were considered for light, medium and heavy traffic volumes respectively. Results obtained were analyzed for elastic modulus in both tension and compression using Hondros Model for short cylinders based on elastic theories. Results obtained revealed that the addition of candle wax into the concretes produced better performance in terms of elastic modulus in both tension and compression at a threshold value of $15 \%$ candle wax for all traffic categories considered. Finally, percentage increases at 15\% candle wax were $74.7 \%$ for elastic modulus in tension and compression - Light Traffic; $85.5 \%$ for elastic modulus in tension and compression - Medium Traffic; $36 \%$ for elastic modulus in tension and compression - Heavy Traffic respectively.
\end{abstract}

Keywords: HMA Concrete, Elastic Modulus, Hondros Model, Stress-Strain, Tensile Split, and Candle Wax

\section{INTRODUCTION}

Hot mix asphalt concretes usually denoted for short as HMA concretes are mostly used in pavement design to simulate how flexible pavements will perform in actual field conditions or real life situations. It is commonly agreed in highway engineering that the performance of actual flexible pavement can be studied or replicated with a good degree of correlation using HMA concretes in the laboratory (You, 2003; You and Buttlar, 2004; Xiao et al., 2007; Xiao et al., 2011).

In previous study by Brown and Foo (1989), it was concluded that in flexible pavement design methods that are based on elastic theories; requires that elastic properties of the materials be determined. The above study corroborates previous studies (Michael and Ramsis, 1988; Baladi and Harichandran, 1988) which summarized some of the stiffness modulus necessary for pavement design as elastic modulus, resilient modulus, dynamic modulus, and dynamic complex modulus. This has been further strengthened by later studies in Garcia and Thompson (2007 \& 2008). The latter posited that the most important HMA property influencing structural responses of HMA concretes and pavements is the stiffness modulus of the concrete.

Therefore, on this basis the present study sought to investigate the variations that will occur in the stiffness of HMA concrete with respect to elastic modulus of the HMA concretes in tension and compression when blended with candle wax under varying percentages using Hondros stress-strain model. For purpose of the study three categories of traffic representing low, medium and heavy traffic volume roads were considered. 


\subsection{Application of Hondros Stress-Strain Theory}

The study by Hondros (1959) as presented in Emesiobi (2000) describes a method for the determination of elastic or Young's modulus from strain measurements at the center of a cylinder when subjected to tensile splitting. His assumptions stated that the properties of the material are the same in tension and compression and is adequate when considerations are made for low values of stresses. The solutions from Hondros model are true for materials within the elastic region based on Hooke's Law of Linearity as presented in Igwe and Pere (2018) which states that "within the elastic region of a given material the ratio of stress to strain is linear and that the slope of the change in stress to strain within the linear region is constant".

Hondros stress-strain model for Elastic Modulus in tension and compression is as presented in Equations $1 \& 2$ below;

a) Elastic Modulus in Tension (Hondros, 1959)

$$
E_{x}=\frac{8 W}{\pi R^{2}\left(3 \varepsilon_{x}+\varepsilon_{y}\right)}
$$

Where

$\mathrm{E}=$ Elastic or Young's Modulus in Tension (MPa)

$\mathrm{W}=$ Load at failure $(\mathrm{N})$

$\varepsilon_{\mathrm{x}}=$ Horizontal Tensile Strain

$\varepsilon_{\mathrm{y}}=$ Vertical Compressive Strain

$\mathrm{R}=$ Radius of cylinder $(\mathrm{mm})$

b) Elastic Modulus in Compression (Hondros, 1959)

$$
E_{y}=\frac{8 W}{\pi R^{2}\left(3 \varepsilon_{y}+\varepsilon_{x}\right)}
$$

Where

$\mathrm{E}=$ Elastic or Young's Modulus in Compression (MPa)

$\mathrm{W}=$ Load at failure $(\mathrm{N})$

$\varepsilon_{\mathrm{x}}=$ Horizontal Tensile Strain

$\varepsilon_{\mathrm{y}}=$ Vertical Compressive Strain

$\mathrm{R}=$ Radius of cylinder ( $\mathrm{mm}$ )

\subsection{Objectives}

The objectives of the research were twofold. The first was to determine elastic modulus in tension and compression for HMA concretes modified with candle wax and subjected to tensile splitting. Whereas, the second was to ascertain the variations that will occur in elastic modulus of the HMA concretes in both tension and compression due to candle wax variation in the mixture under splitting tensile loads. Thirdly, to determine the threshold percentage at which candle wax additions can be safely added to produce best performance in terms of elastic modulus.

\section{MATERIALS AND METHOD}

\subsection{Materials}

Materials used for the research included asphalt cement as the bituminous binder, gravel coarse aggregates (gravel) and sand. Furthermore, candle wax recycled from home wastes was used as the modifier for the HMA concrete. 


\subsection{Material Tests}

Preliminary tests in line with stipulated standards were carried out for the materials used and the results are as presented in section 3 below. Tests carried out included specific gravity for the asphalt cement, viscosity, softening point and penetration tests. In addition, sieve analysis and specific gravity tests were carried out for both coarse and fine aggregates. The sieve analysis was used to determine the mechanical gradation of the coarse and fine aggregates which was further used for aggregate blending for sample preparation using straight line method. Finally, specific gravity test was also done for the candle wax.

\subsection{Sample Preparation}

The HMA concretes that simulated actual flexible pavements in the field were prepared in accordance with test method as proposed by Bruce Marshall (Asphalt Institute Manual Series, 1984; National Asphalt Pavement Association, 1982 and Roberts et al, 1996). The procedure involved first the determination of the optimum asphalt content for which design was made for both unblended and candle wax blended HMA concretes. For the candle wax blended HMA concretes modifications were made using candle wax additions of $5-25 \%$ by weight of the asphalt cement at optimum content. Furthermore, compactions using $6.5 \mathrm{~kg}$ rammer falling freely by gravity at $450 \mathrm{~mm}$ height were made on the unblended and candle wax blended HMA concretes depending on traffic category. For light traffic 35 blows were made, 50 for medium and 75 for heavy traffic respectively. After which the sample was extruded and ready for tensile splitting test.

\subsection{Tensile Splitting Test on Cylinder}

The static indirect tensile strength of each specimen was determined using specified procedure (Livneh and Shklarsky, 1962; Breen and Stephens, 1966; ASTM, 1973) were a loading rate of $5 \mathrm{~mm} /$ minute was adopted causing Tensile failure to occur in the horizontal direction as well as compression in the vertical direction in the sample (See Equation 3 above).

The test involved loading $102 \mathrm{~mm}$ diameter and $64 \mathrm{~mm}$ thick specimen using a $13 \mathrm{~mm}$ wide strip to provide a uniform loading in order to produce uniform stress distribution through the diametral axis. The applied load through the diametral axis indirectly created tensile and compressive stresses in both axis (horizontal and vertical direction) and the load at failure of specimen was recorded. In addition, calibrated strain gauges were attached to the samples and deflections from both axis multiplied by appropriate machine factors used to determine the strains in both the horizontal and vertical directions. The values obtained were then used with Hondros model for the determination of elastic modulus in tension and compression respectively.

\section{RESULTS FROM LABORATORY ANALYSIS}

Results from laboratory investigation plus results from analysis of laboratory tests are presented below. Furthermore, calculation sheet from excel upon which elastic modulus (tension and compression) results were obtained using Hondros stress-strain model for linear elastic materials are herein presented;

Table1. Classification Test Results of Materials

\begin{tabular}{|c|c|c|c|c|}
\hline Material & & Asphalt & $\begin{array}{c}\text { Sand candle } \\
\text { Wax }\end{array}$ & Gravel \\
\hline Specific gravity & & 1.06 & $2.80 \quad 0.8$ & 2.56 \\
\hline Grade of binder material & - & $40 / 50$ & - & - \\
\hline Mix proportion (\%) & - & - & 42 & 58 \\
\hline Viscosity of binder (poise) & - & $5.7 *\left(10^{-4}\right)$ & - & - \\
\hline Softening point & - & & - & - \\
\hline Penetration value & - & $\begin{array}{c}41.5^{\circ} \mathrm{C} \\
51.3 \mathrm{~mm}\end{array}$ & - & - \\
\hline
\end{tabular}

Table2. Mix Proportion of Aggregates Blended (ASTM: 1951)

\begin{tabular}{|c|c|c|c|c|}
\hline $\begin{array}{c}\text { Sieve size } \\
(\mathbf{m m})\end{array}$ & $\begin{array}{c}\text { Specification } \\
\text { limit }\end{array}$ & $\begin{array}{c}\text { Aggregate A } \\
\text { (Gravel) }\end{array}$ & $\begin{array}{c}\text { Aggregate B } \\
\text { (Sand) }\end{array}$ & $\begin{array}{c}\text { Mix proportion } \\
(\mathbf{0 . 5 9 A + 0 . 4 1 B})\end{array}$ \\
\hline 19.0 & 100 & 99.1 & 100 & 99.45 \\
\hline 12.5 & $86-100$ & 86.1 & 100 & 91.80 \\
\hline
\end{tabular}


Evaluation of Modulus of Elasticity of Candle Wax Modified HMA Concretes Using Hondros Model from Indirect Tensile Test

\begin{tabular}{|c|c|c|c|c|}
\hline 9.5 & $70-90$ & 57.5 & 100 & 74.93 \\
\hline 6.3 & $45-70$ & 21.8 & 90 & 53.86 \\
\hline 4.75 & $40-60$ & 7.5 & 99.5 & 45.22 \\
\hline 2.36 & $30-52$ & 3.5 & 97.3 & 41.96 \\
\hline 1.18 & $22-40$ & 2.3 & 92.3 & 39.20 \\
\hline 0.6 & $16-30$ & 1.8 & 69 & 29.30 \\
\hline 0.3 & $9-19$ & 1.4 & 28.2 & 12.39 \\
\hline 0.15 & $3-7$ & 1 & 8.4 & 4.0 \\
\hline 0.075 & 0 & 0.6 & 0.8 & 0.68 \\
\hline
\end{tabular}

Table3. Elastic Modulus of Asphalt Concrete for Light Volume Traffic

\begin{tabular}{|c|c|c|c|c|c|c|c|c|c|}
\hline $\begin{array}{c}\text { Candle } \\
\text { Wax } \\
(\%)\end{array}$ & $\begin{array}{c}\varepsilon_{\mathrm{y}} \\
\left(10^{-4}\right)\end{array}$ & $\begin{array}{c}\mathcal{E}_{\mathrm{x}} \\
\left(10^{-4}\right)\end{array}$ & $3 \varepsilon_{\mathrm{y}}+\varepsilon_{\mathrm{x}}$ & $3 \varepsilon_{x}+\varepsilon_{y}$ & $\begin{array}{l}\text { W } \\
(\mathrm{N})\end{array}$ & $\begin{array}{c}Л R^{2} \\
\left(\mathrm{~N} / \mathrm{mm}^{2}\right)\end{array}$ & $\mathrm{E}_{\mathrm{T}}(\mathrm{MPa})$ & $\begin{array}{c}\mathrm{E}_{\mathrm{c}} \\
(\mathrm{MPa})\end{array}$ & $\mathrm{E}_{\mathrm{T}} / \mathrm{E}_{\mathrm{c}}$ \\
\hline 0 & 2.6125 & 1.254 & 0.00090915 & 0.00063745 & 3,228 & 8172.342 & 4957.14 & 3475.69 & 1.43 \\
\hline 5 & 2.425 & 1.164 & 0.0008439 & 0.0005917 & 3,455 & 8172.342 & 5715.97 & 4007.75 & 1.43 \\
\hline 10 & 2.1541 & 1.034 & 0.00074965 & 0.000525617 & 4,126 & 8172.342 & 7684.29 & 5387.83 & 1.43 \\
\hline 15 & 2.0333 & 0.976 & 0.0007076 & 0.000496133 & 4,390 & 8172.342 & 8661.83 & 6073.24 & 1.43 \\
\hline 20 & 2.3583 & 1.132 & 0.0008207 & 0.000575433 & 3,980 & 8172.342 & 6770.67 & 4747.25 & 1.43 \\
\hline 25 & 2.6333 & 1.264 & 0.0009164 & 0.000642533 & 3,410 & 8172.342 & 5195.20 & 3642.61 & 1.43 \\
\hline
\end{tabular}

NOTE: ET and EC are Elastic Modulus in Tension and Compression respectively

Table4. Elastic Modulus of Asphalt Concrete for Medium Volume Traffic

\begin{tabular}{|c|c|c|c|c|c|c|c|c|c|}
\hline $\begin{array}{c}\text { Candle } \\
\text { Wax } \\
(\%)\end{array}$ & $\begin{array}{c}\varepsilon_{\mathrm{y}} \\
\left(10^{-4}\right)\end{array}$ & $\begin{array}{c}\varepsilon_{\mathrm{x}} \\
\left(10^{-4}\right)\end{array}$ & $3 \varepsilon_{\mathrm{y}}+\varepsilon_{\mathrm{x}}$ & $3 \varepsilon_{\mathrm{x}}+\varepsilon_{\mathrm{y}}$ & $\begin{array}{c}\mathrm{W} \\
(\mathrm{N})\end{array}$ & $\begin{array}{c}\pi^{2} \\
\left(\mathrm{~N} / \mathrm{mm}^{2}\right)\end{array}$ & $\mathrm{E}_{\mathrm{T}}(\mathrm{MPa})$ & $\begin{array}{c}\mathrm{E}_{\mathrm{c}} \\
(\mathrm{MPa})\end{array}$ & $\mathrm{E}_{\mathrm{T}} / \mathrm{E}_{\mathrm{c}}$ \\
\hline 0 & 2.7867 & 1.254 & 0.0009614 & 0.000654867 & 4,996 & 8172.342 & 7468.15 & 5087.00 & 1.46809 \\
\hline 5 & 2.5867 & 1.164 & 0.0008924 & 0.000607867 & 5,312 & 8172.342 & 8554.47 & 5826.96 & 1.46809 \\
\hline 10 & 2.2978 & 1.034 & 0.00079273 & 0.000539978 & 6,357 & 8172.342 & 11524.44 & 7849.98 & 1.46809 \\
\hline 15 & 2.1689 & 0.976 & 0.00074827 & 0.000509689 & 7,214 & 8172.342 & 13855.25 & 9437.64 & 1.46809 \\
\hline 20 & 2.5156 & 1.132 & 0.00086787 & 0.000591156 & 5,950 & 8172.342 & 9852.78 & 6711.31 & 1.46809 \\
\hline 25 & 2.8089 & 1.264 & 0.00096907 & 0.000660089 & 4,855 & 8172.342 & 7199.96 & 4904.32 & 1.46809 \\
\hline
\end{tabular}

NOTE: ET and EC are Elastic Modulus in Tension and Compression respectively

Table5. Elastic Modulus of Asphalt Concrete for Heavy Volume Traffic

\begin{tabular}{|c|c|c|c|c|c|c|c|c|c|}
\hline $\begin{array}{c}\text { Candle } \\
\text { Wax } \\
(\%)\end{array}$ & $\begin{array}{c}\varepsilon_{\mathrm{y}} \\
\left(10^{-4}\right)\end{array}$ & $\begin{array}{c}\varepsilon_{\mathrm{x}} \\
\left(10^{-4}\right)\end{array}$ & $\begin{array}{l}3 \varepsilon_{\mathrm{y}}+\varepsilon_{\mathrm{x}} \\
3 \varepsilon_{\mathrm{x}}+\varepsilon_{\mathrm{y}}\end{array}$ & $\begin{array}{c}\mathrm{W} \\
(\mathrm{N})\end{array}$ & $\begin{array}{c}\pi^{2} \\
\left(\mathrm{~N} / \mathrm{mm}^{2}\right)\end{array}$ & $\mathrm{E}_{\mathrm{T}}(\mathrm{MPa})$ & $\mathrm{E}_{\mathrm{c}}(\mathrm{MPa})$ & $\mathrm{E}_{\mathrm{T}} / \mathrm{E}_{\mathrm{c}}$ \\
\hline 0 & 2.64 & 1.056 & 0.0008976 & 0.0005808 & 8,512 & 8172.342 & 14346.58 & 9283.08 & 1.54546 \\
\hline 5 & 2.5 & 1.000 & 0.00085 & 0.00055 & 8,935 & 8172.342 & 15902.86 & 10290.09 & 1.54546 \\
\hline 10 & 2.4075 & 0.963 & 0.00081855 & 0.00052965 & 9,570 & 8172.342 & 17687.50 & 11444.85 & 1.54546 \\
\hline 15 & 2.2775 & 0.911 & 0.00077435 & 0.00050105 & 9,985 & 8172.342 & 19507.90 & 12622.76 & 1.54546 \\
\hline 20 & 2.44 & 0.976 & 0.0008296 & 0.0005368 & 9,460 & 8172.342 & 17251.31 & 11162.61 & 1.54546 \\
\hline 25 & 2.65 & 1.06 & 0.000901 & 0.000583 & 8,345 & 8172.342 & 14012.04 & 9066.61 & 1.54546 \\
\hline
\end{tabular}

NOTE: ET and EC are Elastic Modulus in Tension and Compression respectively

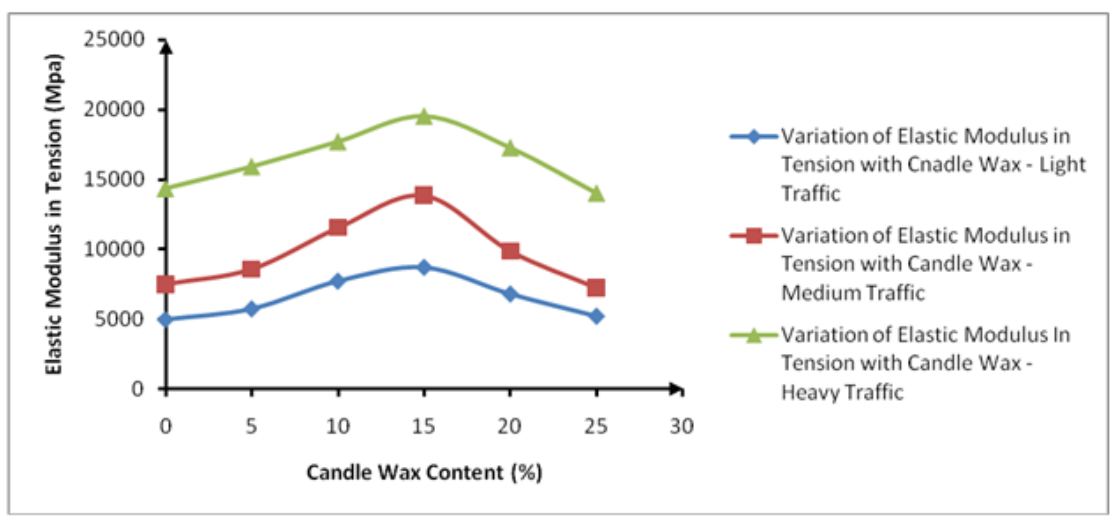

Figure1. Variation of Elastic Modulus in Tension with Candle Wax Content 


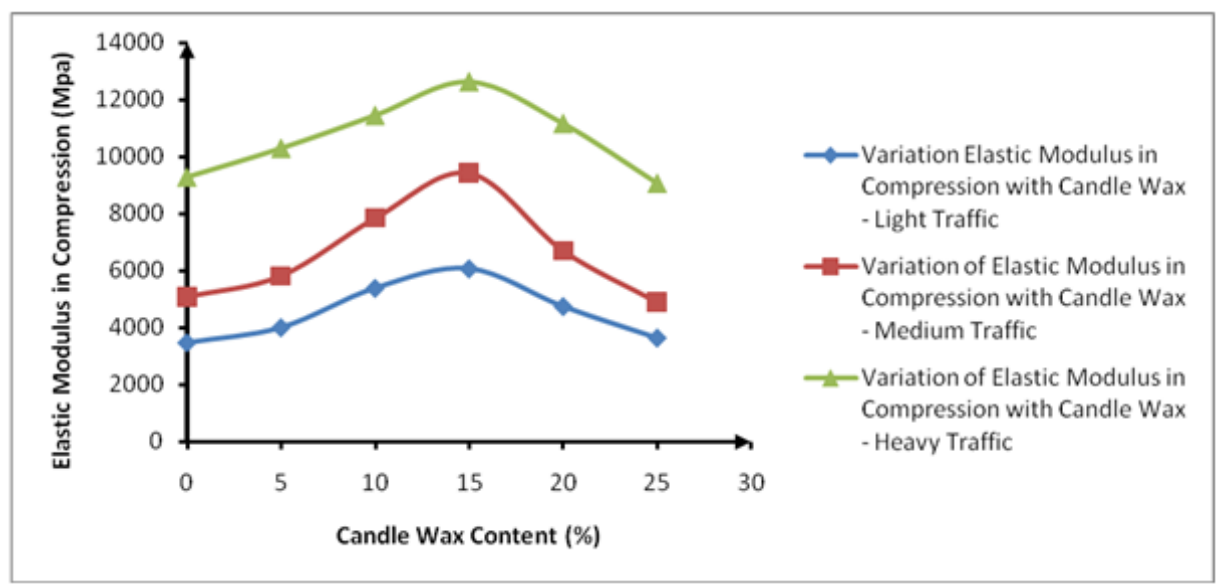

Figure2. Variation of Elastic Modulus in Compression with Candle Wax Content

\section{FINDINGS}

\subsection{Elastic Modulus for Light Volume Traffic}

\subsubsection{Elastic Modulus in Tension}

The results from Table 1 and Figure 1 as presented above revealed that the elastic modulus of the HMA concretes in tension varied increasingly with increasing additions of candle wax into the mixture up to $15 \%$ additions, with an optimum value of $8661.83 \mathrm{Mpa}$. However, further additions of the wax resulted in a decrease in elastic modulus of the concretes in tension. The implication is that at the optimum value; the elastic modulus of the HMA concretes in tension at $15 \%$ candle wax addition resulted in a $74.7 \%$ increase in the original value of elastic modulus of the unblended HMA concretes in tension.

\subsubsection{Elastic Modulus in Compression}

The results from Table 1 and Figure 2 as presented above revealed that the elastic modulus of the HMA concretes in compression varied increasingly with increasing additions of candle wax into the mixture up to $15 \%$ additions, with an optimum value of $6073.24 \mathrm{Mpa}$. However, further additions of the wax resulted in a decrease in elastic modulus of the concretes in compression. The implication is that at the optimum value; the elastic modulus of the HMA concretes in compression at $15 \%$ candle wax addition resulted in a $74.7 \%$ increase in the original value of elastic modulus of the unblended HMA concretes in compression.

\subsection{Elastic Modulus for Medium Volume Traffic}

\subsubsection{Elastic Modulus in Tension}

The results from Table 2 and Figure 1 as presented above revealed that the elastic modulus of the HMA concretes in tension varied increasingly with increasing additions of candle wax into the mixture up to $15 \%$ additions, with an optimum value of $13855.25 \mathrm{Mpa}$. However, further additions of the wax resulted in a decrease in elastic modulus of the concretes in tension. The implication is that at the optimum value; the elastic modulus of the HMA concretes in tension at $15 \%$ candle wax addition resulted in a $85.5 \%$ increase in the original value of elastic modulus of the unblended HMA concretes in tension.

\subsubsection{Elastic Modulus in Compression}

The results from Table 2 and Figure 2 as presented above revealed that the elastic modulus of the HMA concretes in compression varied increasingly with increasing additions of candle wax into the mixture up to $15 \%$ additions, with an optimum value of $9437.64 \mathrm{Mpa}$. However, further additions of the wax resulted in a decrease in elastic modulus of the concretes in compression. The implication is that at the optimum value; the elastic modulus of the HMA concretes in compression at $15 \%$ candle wax addition resulted in a $85.5 \%$ increase in the original value of elastic modulus of the unblended HMA concretes in compression. 


\subsection{Elastic Modulus for Heavy Volume Traffic}

\subsubsection{Elastic Modulus in Tension}

The results from Table 3 and Figure 1 as presented above revealed that the elastic modulus of the HMA concretes in tension varied increasingly with increasing additions of candle wax into the mixture up to $15 \%$ additions, with an optimum value of $19507.90 \mathrm{Mpa}$. However, further additions of the wax resulted in a decrease in elastic modulus of the concretes in tension. The implication is that at the optimum value; the elastic modulus of the HMA concretes in tension at $15 \%$ candle wax addition resulted in a $36 \%$ increase in the original value of elastic modulus of the unblended HMA concretes in tension.

\subsubsection{Elastic Modulus in Compression}

The results from Table 3 and Figure 2 as presented above revealed that the elastic modulus of the HMA concretes in compression varied increasingly with increasing additions of candle wax into the mixture up to $15 \%$ additions, with an optimum value of $12622.76 \mathrm{Mpa}$. However, further additions of the wax resulted in a decrease in elastic modulus of the concretes in compression. The implication is that at the optimum value; the elastic modulus of the HMA concretes in compression at $15 \%$ candle wax addition resulted in a $36 \%$ increase in the original value of elastic modulus of the unblended HMA concretes in compression.

In summary, the phenomenon behind the changes in elastic modulus is traceable to the fact that candle wax has nearly the same predominant chemical composition (carbon and hydrogen compounds) as the asphalt cement binder (Van-Rooijen, 1938; Igwe and Ottos, 2017). In addition, under heat the carbon and hydrogen molecules in both candle wax and the asphalt cement used as binder become highly miscible and increases binding action in the HMA concretes. Furthermore, increased binding action in the concretes will normally result to reduced strains in the concretes under loading conditions of traffic and temperature thereby increasing elasticity of the concretes.

\section{CONCLUSION}

From the findings of the study based on laboratory investigations carried out together with analysis made the following conclusions were made;

- That the addition of candle wax into HMA concrete mixtures produced better performance in terms of input parameters for mechanistic design with respect to elastic modulus in tension.

- That the addition of candle wax into HMA concrete mixtures produced better performance in terms of input parameters for mechanistic design with respect to elastic modulus in compression.

- That in order to produce HMA concretes with optimum performance, candle wax addition shall not be more than $15 \%$ by weight of the asphalt cement whether in tension or compression.

- Finally, it was concluded that the percentage change in elastic modulus in tension is the same as that in compression for each traffic category considered.

\section{REFERENCES}

[1] ASTM C-469 (1973) "Static Modulus of Elasticity and Poisson's Ratio of Concrete in Compression”, pp. 280-283

[2] Baladi, G. Y. and Harichandran S. R, (1988) 'Asphalt Mix Design and the Indirect Test': A NewHorizon.

[3] Breen, J. J. and Stephens, J. E. (1966) "Split Cylinder Test Applied to Bituminous Mixtures at Low Temperature", Journal of Materials, American Society for Testing Materials, Vol. 1, No.1

[4] Brown, E. R. and Foo, K. Y. (1989) "Evaluation of Variability in Resilient Modulus Test Results",(ASTM D 41 23) National Centre for Asphalt Technology: Report No. 91-6.

[5] Emesiobi, F. C. (2000) "Elastic Properties of Highway Pavement Materials: Testing and Quality Control of Materials in Civil and Highway Engineering", Chapter 7, p.246, Port Harcourt, Nigeria, Blue Print Limited.

[6] Garcia, G., and Thompson M. R., (2007) "HMA Dynamic Modulus Predictive Models: A Review”,Report of the Findings of ICt-R39: Validation of Extended Life HMA design Concepts, Research Report FHWAICT-07-005. 
[7] Garcia, G., and Thompson M. R., (2008) "Strain and Pulse Duration Considerations for Extended Hot Mix Asphalt Pavement Design", Proceedings of the 87th Annual Meeting of the Transportation Research Board, Washington, D.C.

[8] Hondros, G. (1959) “The Evaluation of Poisson's Ratio and the Modulus of Materials of Low Tensile Resistance by the Brazilian Test, Australian Journal of Applied Science, Vol. 100, No. 3, pp. 243-268.

[9] Igwe, E. A. (2015) "Influence of Candle Wax on Stiffness of Hot Mix Asphalt Concrete: Light Traffic Case Study", Global Advanced Research Journal of Engineering, Technology and Innovation" (ISSN: 2315-5124) Vol. 4, No. 7, pp. 098-104.

[10] Igwe, E. A. (2016) "Tensile Reduction in Asphalt Concrete Mixtures through Rubberization atthe Asphalt Bound - Subgrade Layer Interface”, "International Journal of Concrete Technology", Vol. 2, Issue 1, pp. $44-53$.

[11] Igwe, E. A. and Ottos, C. G. (2017) "Increasing Durability of Bituminous Pavements using HydroCarbon Void Fillers produced from Recycled Polyethylene Wastes (RPEW)", Journal of Scientific and Engineering Research, Vol. 4, Issue 12, pp. 24 - 30.

[12] Igwe, E. A. and Pere, K. F. (2018) “Timoshenko's Stress-Strain Application In Determining the Variation of Tensile Elastic Modulus in Flexible Pavements Modified with Candle Wax and Subjected to Diametral Split”, The International Journal of Engineering and Science, Volume 7, Issue 6, Ver. III, pp. 01-05.

[13] Livneh, M. and Shklarsky, E. (1962) "The Splitting Test for Determination of Bituminous Concrete Strength", Proceedings, Association of Paving Technologists, Vol. 31, pp. $457-476$.

[14] Michael, M. S. and Ramsis, S. T. (1988) „The Modulus of Asphalt Mixtures - An Unresolved Dilemma Transportation Research Board, 67th annual meeting.

[15] National Asphalt Pavement Association (1982) "Development of Marshall Procedures for Designing Asphalt Paving Mixtures”, Information Series 84, National Asphalt Pavement Association Lanham, MD.

[16] Oguara, T. M. (1985) "Mechanistic Approach to Design of Highway Pavements in Nigeria", ISSMFE, Golden Jubilee Publication on Geotechnical Practice in Nigeria, Lagos, pp. 139-154.

[17] Roberts, F. L. Kandhal, P. S., Brown, E. R.; Lee, D. Y. and Kennedy, T. W., (1996) "Hot Mix Asphalt Materials, Mixture Design, and Construction" National Asphalt Pavement Association Education Foundation Lanham, MD.

[18] Van-Rooijen, J. M. (1938) "The Effect of Rubber upon some Properties of Asphaltic Bitumen", Rubber Foundation Communication No. 7, Amsterdam.

[19] Xiao, F., Amirkhanian, S. and Juang, H. (2007) " Prediction of Fatigue Life of Rubberized Asphalt Concrete Mixtures Containing Reclaimed Asphalt Pavement Using Artificial Neural Networks" ASCE Journal of Materials in Civil engineering, (MT/023481)

[20] Xiao, F., Amirkhanian, S.N. and Wu, B. (2011) "Fatigue and Stiffness Evaluations of Reclaimed Asphalt Pavement in Hot Mix Asphalt Mixtures", Journal of Testing and Evaluating, vol. 39, Issue 1, p.9.

[21] You, Z. (2003) Development of a Micromechanical Modelling Approach to Predict Asphalt Mixture Stiffness Using the Discrete Element Method. Thesis $(P h D)$, University of Illinois at Urbana-Champaign.

[22] You, Z., and Buttlar, W. G. (2004) "Discrete-element modeling to predict the modulus of asphalt concrete mixtures.” Journal of Material in Civil Engineering, vol. 16, Issue 2, pp.140-146.

Citation: Enwuso Aleruchi Igwe, Pere Kormane Fun-Akpo, "Evaluation of Modulus of Elasticity of Candle Wax Modified HMA Concretes Using Hondros Model from Indirect Tensile Test”, International Journal of Constructive Research in Civil Engineering, 6(1), pp. 37-43. DOI: http://dx. doi.org/10.20431/24548693.0601004.

Copyright: (C) 2020 Authors, This is an open-access article distributed under the terms of the Creative Commons Attribution License, which permits unrestricted use, distribution, and reproduction in any medium, provided the original author and source are credited. 